\title{
EFFECT OF ORAL MOXONIDINE IN THE ATTENUATION OF THE HAEMODYNAMIC RESPONSES SEEN DURING LAPAROSCOPIC SURGERIES
}

\author{
SIDHARTH SRABAN ROUTRAY ${ }^{*}$, RAMAKANTA MOHANTY ${ }^{2}$ \\ ${ }^{1}$ Department of Anesthesiology and Critical Care, SCB Medical College and Hospital, Cuttack, Odisha, India. ${ }^{2}$ Department of Surgery, \\ SCB Medical College and Hospital, Cuttack, Odisha, India. Email: drkitusraban@gmail.com
}

Received: 28 November 2016, Revised and Accepted: 21 December 2016

\section{ABSTRACT}

Objective: During laparoscopic surgeries, pneumoperitoneum can lead to various pathophysiologic changes in the cardiovascular system resulting in hypertension and tachycardia. Search for ideal drug to prevent this hemodynamic response goes on. The aim of our study was to evaluate the effect of orally administered moxonidine in attenuating the hemodynamic responses that occur during the laparoscopic surgeries.

Methods: A total of 50 adult acetylsalicylic acid I and II patients scheduled for elective laparoscopic surgeries were selected for this prospective randomized double-blinded study. They were randomly allocated into two groups: moxonidine group (M) and placebo group (P). M group received oral moxonidine $0.3 \mathrm{mg}$ at $8 \mathrm{pm}$ on the day before surgery and at $8 \mathrm{am}$ on the day of surgery. P group received a placebo at the same timing as that of the M group.

Results: Following pneumoperitoneum rise in systolic blood pressure (SBP), diastolic BP (DBP), mean arterial pressure (MAP), and heart rate (HR) was higher in P group in comparison to M group which was statistically significant.

Conclusion: Significant rise in HR, SBP, DBP, and mean BP was noted in the P group in comparison to moxonidine group. Moxonidine provided better perioperative hemodynamic stability in patients undergoing laparoscopic surgeries.

Keywords: Moxonidine, Stress response, Laparoscopic.

(c) 2017 The Authors. Published by Innovare Academic Sciences Pvt Ltd. This is an open access article under the CC BY license (http://creativecommons. org/licenses/by/4. 0/) DOI: http://dx.doi.org/10.22159/ajpcr.2017.v10i3.16383

\section{INTRODUCTION}

Laparoscopic surgeries are the most commonly performed surgeries in general surgery. Overall, complication rate is $<1.5 \%$, and the mortality rate is 3.3 times greater in laparoscopic surgeries mainly due to pneumoperitoneum, compared to invasive surgeries [1]. Laparoscopic surgeries require pneumoperitoneum for which general anesthesia with endotracheal intubation and intermittent positive pressure ventilation is required. The pneumoperitoneum created for laparoscopy produces complex physiologic changes that can make anesthetic management more difficult [2]. The pathophysiologic changes resulting from pneumoperitoneum are directly related to clinical outcome. These changes include increase in the heart rate (HR), increase in mean arterial pressure (MAP) and decrease in cardiac output due to increase in systemic vascular resistance (SVR) resulting in reduced tissue perfusion. Various techniques and pharmacological agents have been used to counteract these detrimental effects of pneumoperitoneum. These changes are tolerated in ASA I and II patients but it can be detrimental in elderly and ASA III and more grade patients particularly with compromised cardiovascular system. Various techniques and pharmacological agents have been used to counteract these life-threatening complications of pneumoperitoneum. These included gasless laparoscopy, use of $\beta$-adrenergic blockers, nitroglycerine, calcium channel blockers, and $\alpha-2$ agonists such as clonidine and dexmedetomidine but none was found to be ideal in completely reducing the side effects of pneumoperitoneum [3].

Moxonidine, a centrally acting antihypertensive drug has a weak affinity for the $\alpha_{2}$-adrenoceptor and is generally described as a selective $\mathrm{I}_{1}$-imidazoline receptor $\left(\mathrm{I}_{1} \mathrm{R}\right)$ agonist that lowers blood pressure (BP) by decreasing sympathetic activity within the central nervous system [4]. It acts on the rostral ventrolateral medulla and decrease the sympathetic nervous system activity as measured by serum norepinephrine, and plasma renin activity [5]. Various studies have shown that moxonidine reduces arterial pressure by lowering SVR while sparing HR, cardiac output, and stroke volume. In this study, orally administered moxonidine was evaluated for its impact on hemodynamic response that occurs during pneumoperitoneum in laparoscopic surgeries.

\section{METHODS}

After approval of the Institutional Ethics Committee and written informed consent, 70 patients, scheduled for elective laparoscopic surgeries under general anesthesia were enrolled for this double-blind prospective randomized study. Group M: Received moxonidine $0.3 \mathrm{mg}$ at $8 \mathrm{pm}$ the day before surgery and at 8 am on the day of surgery. Group P: Received placebo at $8 \mathrm{pm}$ on the day before surgery and at $8 \mathrm{am}$ on the day of surgery. 70 healthy adult patients of ASA physical status I and II of either sex aged 20 to 60 years and weighing 50 to $90 \mathrm{Kg}$ were included in this study. Patients with hypertension, history of cardiac, pulmonary, hepatic or renal disease, psychiatric disorder, body mass index $>30$, and patients with difficult airway were excluded from this study. Routine investigations such as hemogram, complete blood analysis, liver function tests, serum electrolytes, serum protein, $\mathrm{X}$-ray chest, and preoperative electrocardiogram were done and were analyzed. Patients were kept nil orally for 6 hrs preoperatively. They were randomly assigned to one of the two groups to receive either moxonidine $0.3 \mathrm{mg}$ or placebo at $8 \mathrm{pm}$ on the day before surgery and at 8 am on the day of surgery. Infusion of ringer lactate solution was started after intravenous cannulation. The patients were premedicated with fentanyl ( $2 \mu \mathrm{g} / \mathrm{kg}$ ), glycopyrrolate $(0.004-0.006 \mathrm{mg} / \mathrm{kg})$, and midazolam $(0.03-0.05 \mathrm{mg} / \mathrm{kg}) 30$ minutes before induction. After shifting to the operation theater, the patients were connected to noninvasive BP monitor, pulse oximeter, capnograph and electrocardiograph, and baseline parameters were recorded. All patients were preoxygenated 
with 100\% oxygen for 3 minutes. Induction of anesthesia was done with propofol $(2 \mathrm{mg} / \mathrm{kg})$, and intubation was facilitated using vecuronium bromide $(0.08-0.12 \mathrm{mg} / \mathrm{Kg})$. Anesthesia was maintained with vecuronium bromide $(0.02 \mathrm{mg} / \mathrm{Kg})$ and intermittent positive pressure ventilation with nitrous oxide and oxygen in the ratio of 2:1 with $0.6 \%$ isoflurane. Pneumoperitoneum was created and maintained by insufflations of carbon dioxide.

The table was tilted depending on the requirement of surgery. Intraabdominal pressure was maintained between $12-15 \mathrm{~mm} \mathrm{Hg}$ during the surgery. Throughout the study period, all the parameters selected (HR, systolic BP [SBP], diastolic BP [DBP], MAP $\mathrm{SpO}_{2}$, and $\mathrm{ETCO}_{2}$ ) were recorded. Any change in hemodynamic variables more than $20 \%$ on either side of baseline was considered significant. Any increase in MAP up to $20 \%$ from baseline was treated by increasing the concentration of isoflurane to a maximum $2 \%$ or nitroglycerine infusion so as to maintain the MAP within $20 \%$ of baseline. Time duration from creation of pneumoperitoneum to the release of pneumoperitoneum was taken as duration of pneumoperitoneum. At the end of surgery, neuromuscular blockade was reversed with IV neostigmine $60 \mu \mathrm{g} / \mathrm{kg}$ and glycopyrrolate $10 \mu \mathrm{g} / \mathrm{kg}$. After extubation, the patients were transferred to postanesthesia care unit. All patients were assessed for changes in hemodynamic parameters (HR, SBP, DBP, and MAP) before premedication and induction, after laryngoscopy and intubation. After pneumoperitoneum, same parameters were recorded at 5 minutes interval for 10 minutes, followed by every 10 minutes for 40 minutes, then thereafter every 20 minutes until end of pneumoperitoneum. The results were expressed as mean \pm standard deviation which was calculated for all quantitative variables using SPSS statistical software version 16. Comparison between two groups was done using Student's unpaired $t$-test. $\mathrm{p}<0.05$ was considered statistically significant.

\section{Observation}

There were no significant differences were found with respect to age, weight, and gender, ASA status and duration of surgery (Table 1).

The mean pulse rate at 5 minutes, 10 minutes, 20 minutes, 30 minutes, 40 minutes, and 60 minutes after pneumoperitoneum is lower in moxonidine group than Placebo group. The results were statistically significant $(\mathrm{p}<0.05)($ Graph 1$)$.

Graph 2 compares the mean SBP between moxonidine and P group at various time intervals during the surgery. Mean SBP was lower in $\mathrm{M}$ group compared to $\mathrm{P}$ group which was statistically significant $(\mathrm{p}<0.05)$.

Graph 3 compares the mean diastolic BP between moxonidine and $P$ group at various intervals during the surgery. Mean DBP was lower in $\mathrm{M}$ group compared to $\mathrm{P}$ group which was statistically significant $(\mathrm{p}<0.05)$.

Graph 4 compares the mean arterial BP recorded at various intervals during the surgery. MAP was lower in M group compared to $\mathrm{P}$ group at different time interval which was statistically significant $(p<0.05)$.

\section{DISCUSSION}

Pneumoperitoneum during the laparoscopic surgery can lead to significant hemodynamic changes such as an increase in MAP and SVR and a decrease in cardiac output [6]. These hemodynamic responses can result in complications such as myocardial ischemia, cerebral hemorrhage, and difficulty in mechanical ventilation of patients. Moxonidine is a centrally acting antihypertensive drug that reduces arterial BP by inhibiting central sympathetic activity [7]. Its chemical formula is 4-chloro-N-(imidazolidin-2-ylidene)-6-methoxy2-methyl-5-pyrimidinamine. Its empirical formula is $\mathrm{C}_{9} \mathrm{H}_{12} \mathrm{CIN}_{5} \mathrm{O}$ and its molecular weight is 241.68 [8]. Moxonidine is an imidazoline compound which acts on $\mathrm{I}_{1} \mathrm{R}$ in the central nervous system to reduce sympathetic activity and BP. Farsang, his review of moxonidine, concluded that it suppresses sympathetic tone and effectively reduces $\mathrm{BP}$ for at least $24 \mathrm{hrs}$, and therefore, it can be administered once daily [9]. Joris et al. investigated hemodynamic changes induced by carbon dioxide insufflations in pneumoperitoneum and concluded that vasopressin and catecholamines are probable mediators in increasing the SVR observed during pneumoperitoneum. They concluded that clonidine can modulate the hemodynamic changes due to pneumoperitoneum [10]. Koivusalo et al., in their study, have shown that postoperative recovery after laparoscopic cholecystectomy was faster and uneventful when carbon dioxide was not used for

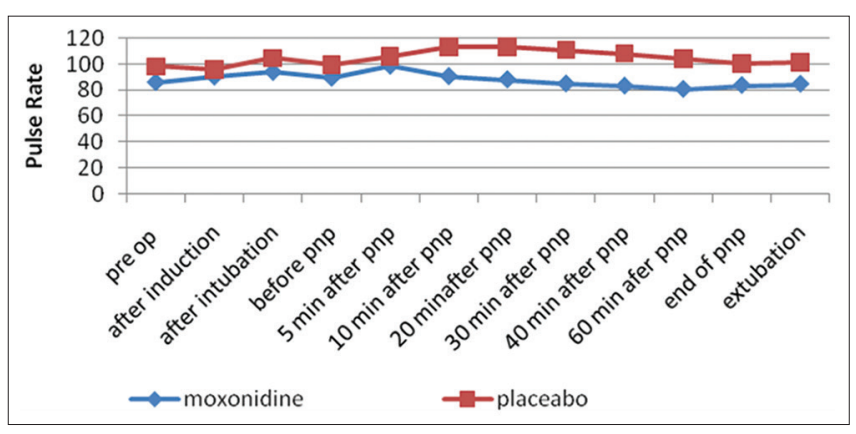

Graph 1: Changes in mean pulse rate

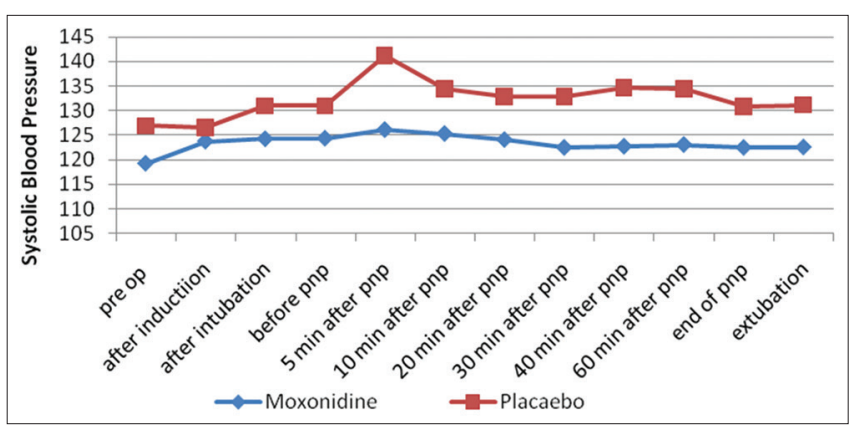

Graph 2: Changes in mean systolic blood pressure

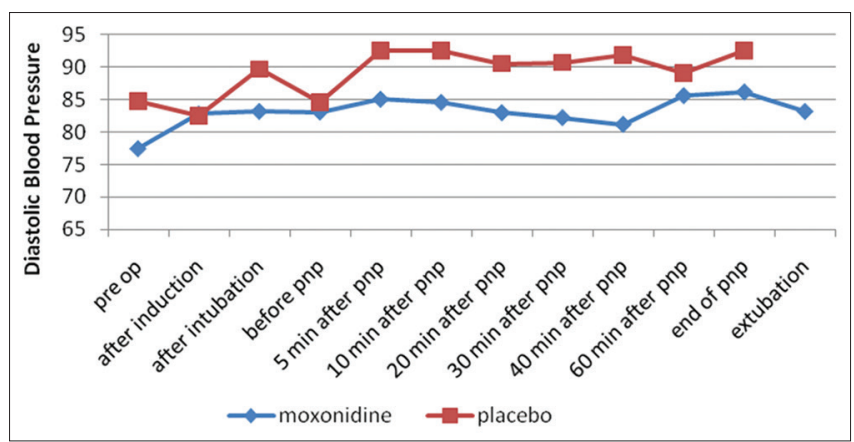

Graph 3: Changes in mean diastolic blood pressure

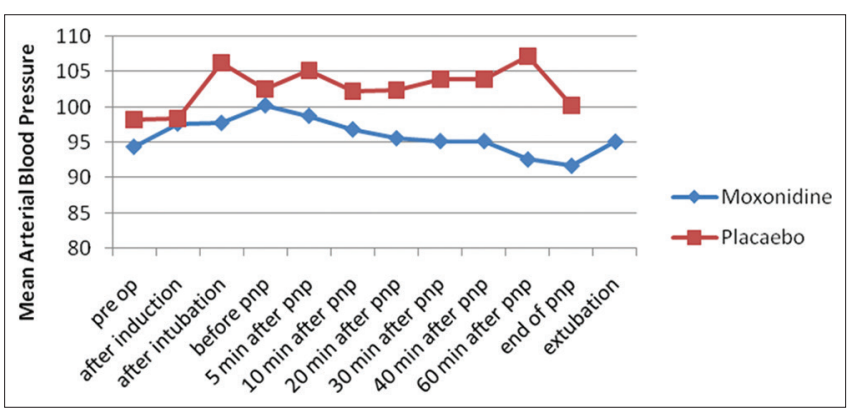

Graph 4: Changes in mean arterial pressure 
Table 1: Demographic profile

\begin{tabular}{llll}
\hline Parameter & Moxonidine & Placebo & p \\
\hline Age & $41.24 \pm 6.17$ & $41 \pm 7.35$ & 0.9 \\
Sex (M/F) & $12: 13$ & $11: 14$ & 0.8 \\
Weight & $66.32 \pm 6.38$ & $66.80 \pm 6.08$ & 0.78 \\
ASA status (I/II) & $29 / 6$ & $30 / 5$ & 0.7 \\
Duration of surgery & $45.5 \pm 5.80$ & $46.9 \pm 4.7$ & 0.82 \\
\hline
\end{tabular}

ASA: Acetylsalicylic acid

pneumoperitoneum. They suggested that mechanical abdominal lift method without carbon dioxide insufflations is better for laparoscopic cholecystectomy may be the method of choice while considering laparoscopic cholecystectomy [11]. Fenton et al., in their review, observed that moxonidine acts centrally to reduce central and peripheral sympathetic activity, thus decreasing peripheral vascular resistance. In patients with mild to moderate hypertension, moxonidine reduces BP as effectively as most first-line antihypertensives. It improves the clinical and metabolic profile in patients with hypertension and diabetes mellitus [12]. Malek et al. evaluated the effect of moxonidine on the attenuation of hemodynamic response during laparoscopic cholecystectomy in comparison with clonidine. They had concluded that administration of clonidine in premedication before laparoscopic cholecystectomy provides better results; compared to moxonidine [13]. Sung et al. studied the effect of oral clonidine as premedication on perioperative hemodynamic response and post-operative analgesic requirement for patients undergoing laparoscopic cholecystectomy and observed that oral clonidine premedication helped to provide perioperative hemodynamic stability. It reduced the use of isoflurane and requirement of post-operative analgesia [14]. Das et al. studied the effect of clonidine premedication on hemodynamic changes during laparoscopic cholecystectomy. They concluded that clonidine is safe and effective in providing stable hemodynamics. It protects against stress response due to pneumoperitoneum in patients undergoing laparoscopic cholecystectomy [15]

Bansal and Hooda concluded in his review of newer drugs in anesthesia that clonidine is not only a good antihypertensive but also it provides perioperative hemodynamic stability and obtunds pressure response to endotracheal intubation [16]. Banday and Sameer, in his article, reviewed effect of gabapentin and opined that like clonidine, gabapentin also attenuates hemodynamic stress response to direct laryngoscopy and tracheal intubation [17]. In our study, the overall hemodynamic profile was stable in the moxonidine group when compared to the $\mathrm{P}$ group. The fluctuations in mean pulse rate, SBP, $\mathrm{DBP}$, and MAP were significant throughout the intraoperative period in the moxonidine group compared to $\mathrm{P}$ group. The results obtained in our study are consistent with the previous studies which used clonidine and dexmedetomidine in reducing stress response due to pneumoperitoneum. Moxonidine has a favorable effect on the clinical and metabolic profile in the body. Hence, it can be used in patients having some derangement in the metabolic profile with regard to blood sugar levels, lipid profile, etc. Moxonidine may have an edge over other centrally acting antihypertensive like clonidine and dexmedetomidine due to their side effects like bradycardia and sedation.

\section{CONCLUSION}

The use of moxonidine in laparoscopic surgeries is a promising approach in attenuating the hemodynamic response during the intraoperative period. It not only prevents stress response due to endotracheal intubation and extubation but also facilitates smooth recovery from anesthesia.

\section{REFERENCES}

1. Marco AP, Yeo CJ, Rock P. Anesthesia for a patient undergoing laparoscopic cholecyctectomy. Anesthesiology 1990;73(6):1268-70.

2. Lindgren L, Koivusalo AM, Kellokumpu I. Conventional pneumoperitoneum compared with abdominal wall lift for laparoscopic cholecystectomy. Br J Anaesth 1995;75(5):567-72.

3. Gurusamy KS, Samraj K, Davidson BR. Abdominal lift for laparoscopic cholecystectomy. Cochrane Database Syst Rev 2008;8:CD006574.

4. Feig BW, Berger DH, Doughtery TB, Dupuis JF, Hsi B, Hickey RC, et al. Pharmacological interventions can reestablish baseline hemodynamic parameters during laparoscopy. Surgery 1994;116(4):733-9.

5. Joris J, Chiche JD, Lamy M. Clonidine reduced hemodynamic changes induced by pneumoperitoneum during laparoscopic cholecystectomy. Br J Anaesth 1995;74 Suppl: A124.

6. Aho M, Scheinin M, Lehtinen AM, Erkola O, Vuorinen J, Korttila K. Intramuscularly administered dexmedetomidine attenuates hemodynamic and stress hormone responses to gynecologic laparoscopy. Anesth Analg 1992;75(6):932-9.

7. Shribman AJ, Smith G, Achola KJ. Cardiovascular and catecholamine responses to laryngoscopy with and without tracheal intubation. Br J Anaesth 1987:59(3):295-9.

8. Saif GM, Singh V, Kumar A, Wahal R, Bhatia VK. A study of cardiovascular response during laryngoscopy and intubation and their attenuation by ultra-short acting beta-blocker esmolol. Indian J Anaesth 2002;46(2):104-6

9. Farsang C. Moxonidine: Clinical profile. J Clin Basic Cardiol 2001;4(3):197-200.

10. Joris JL, Chiche JD, Canivet JL, Jacquet NJ, Legros JJ, Lamy ML. Hemodynamic changes induced by laparoscopy and their endocrine correlates: Effects of clonidine. J Am Coll Cardiol 1998;32(5):1389-96.

11. Koivusalo AM, Scheinin M, Tikkanen I, Yli-Suomu T, Ristkari S, Laakso J, et al. Effects of esmolol on hemodynamic responses to $\mathrm{CO} 2$ pneumoperitoneum for laparoscopic surgery. Acta Anaesthesiol Scand 2008;42(5):510-7.

12. Fenton C, Keating GM, Lyseng-Williamson KA. Moxonidine: A review of its use in essential hypertension. Drugs 2006;66(4):477-96.

13. Malek J, Knor J, Kurzova A, Lopourova M. Adverse hemodynamic changes during laparoscopic cholecystectomy and their possible suppression with clonidine premedication. Comparison with intravenous and intramuscular premedication. Rozhl Chir 1999;78(6):286-91.

14. Sung CS, Lin SH, Chan KH, Chang WK, Chow LH, Lee TY. Effect of oral clonidine premedication on perioperative hemodynamic response and postoperative analgesic requirement for patients undergoing laparoscopic cholecystectomy. Acta Anaesthesiol Sin 2000;38(1):23-9.

15. Das M, Ray M, Mukherjee G. Hemodynamic changes during laparoscopic cholecystectomy: Effect of oral clonidine premedication. Indian J Anaesth 2007;51(3):205-10.

16. Bansal T, Hooda S. Newer drugs in anaesthesia. Int J Pharm Pharm Sci 2012;4(1):668-70

17. Banday M, Sameer A. Gabapentine: A pharmacotherapeutic Panacea. Int J Pharm Pharm Sci 2013;5(3):84-94. 